\title{
A Survey on the Iranian ELT Community's Attitudes to Critical Pedagogy
}

\author{
Hossein Davari (Corresponding author) \\ English Department, Payam Nour University, Damghan, Iran \\ Azadegan Sq., Payam Nour University, Damghan, Iran \\ E-mail: hdavari1358@yahoo.com
}

\begin{abstract}
Abutaleb Iranmehr
English Department, Shahrood University of Technology, Shahrood, Iran

University Blvd., Shahrood University of Technology, Shahrood, Iran

E-mail: a_iranmehr946@yahoo.com
\end{abstract}

Seyyed Mahdi Erfani

English Department, Damghan University, Damghan, Iran

Saadi Sq., Damghan University, Damghan, Iran

E-mail: smerfani@yahoo.com

Received: September 12, 2011

Accepted: October 11, 2011

Published: February 1, 2012

doi:10.5539/elt.v5n2p101

URL: http://dx.doi.org/10.5539/elt.v5n2p101

This study was conducted as part of a research project funded by Payam Nour University (PNU), Iran.

\begin{abstract}
Critical pedagogy (CP) as one of the most radical changes in English language teaching (ELT) has turned into a common theme of research and discussion in recent years. Despite its practical implications, however, most of the research on this issue has been limited to its theoretical and conceptual dimensions. Conceiving the importance of this approach as well as considering the practical and applied dimensions of this newly emergent shift in ELT, this study is an attempt to study the Iranian ELT community's attitudes to some practical implications of CP in ELT. To acquire the Iranian ELT community's attitudes, a mixed-method approach was conducted. In the first phase, an interview survey was conducted with 8 applied linguists. Enjoying the content analysis of the data as well as the available literature on the topic, especially Akbari's (2008b) suggestions, a 10 item Likert-scale was prepared. To check the Iranian ELT community in the second phase, a questionnaire survey was conducted on 86 participants. Findings of this phase, as the main source of study, reveals that critical pedagogy is going to find a position in Iranian ELT community.
\end{abstract}

Keywords: Critical Pedagogy (CP), English Language Teaching (ELT), Attitude, Iranian society

\section{Introduction}

In Akbari's (2008a) words, the second language teaching profession has gone through a number of dramatic changes during the last two decades. Certainly one of the topics which has turned into a common theme of discussion and research is critical pedagogy (CP). According to Ford (2009), the last few decades have seen a growing interest in critical pedagogy in both ESL and EFL contexts. Rajagopalan (2000) also asserts that critical pedagogy has won over a growing number of advocates and enthusiasts in recent years.

While the concept of $\mathrm{CP}$ has been around for some time in education, it has been recently explored in the practice of English language teaching (ELT). In fact, CP as a new approach in ELT is known as one which places sociopolitical considerations high on the classroom agenda (Ford, 2009) and incorporates a set of principles and practices that aim not only to change the nature of schooling, but also the wider society (Pennycook, 1990). 
Reviewing the literature on the topic reveals that the scholars within the broad and somewhat diverse critical pedagogy tradition have tried to intensify the discussion of the political and sociocultural implications that permeate English language teaching (Cox and Assis-Peterson, 1999). In a more precise word, the major concern of the advocates of CP is with the dominant discourse in ELT that considers the expansion and internationalization of English and the global spread of mainstream ELT practices and principles as natural, neutral and beneficial (Pennycook, 1994).

According to the writers within the CP tradition such as Canagarajah (1999), Pennycook (1994) and Philipson (1992), the absence of a critical view toward the teaching and the role of English seems to be a result of English teachers' submission to applied linguists which has emphasized some formal and methodological issues as well as some mostly unquestioned tenets. Following the appearance of this critical approach, today it is not surprising to see some controversy and discussion surrounding ELT as the most systematic way of spreading English throughout the world (Davari, 2011).

In fact, this critical and intellectual shift in applied linguistics that began in the early years of 1990s, as Anderson (2003) writes, saw its symbolic birth with the appearance of Philipson's Linguistic Imperialism in 1992 which was not the first publication to raise the issues it does, but qualitatively it seems to have had the most impact. According to Davari (2011), the outstanding appearance of this critical shift in ELT not only has significantly challenged and complicated the mainstream ELT, but also has mostly introduced critical pedagogy as an alternative approach to the mainstream ELT.

Prior to this intellectual shift in the domain of applied linguistics, as Anderson (2003) writes, there were certain unquestioned tenets in the professional-academic discourse associated with the global spread of English. Such tenets were produced and reproduced by English teachers, their professional associations, as well as by academics, institutions and by mainly British and American publishing companies that produce teacher education publications and teaching materials. In such a situation, the outstanding advent of critical pedagogy tradition challenged the mainstream ELT which as Pennycook (1994) writes, for much of its history has been subject to the heavy "evangelical zeal" of the Center or the Inner Circle who has exported its theories, methods, approaches, materials and books to the Periphery often with doubtful relevance to the sociological, educational and economic context of Outer and Expanding Circle Countries.

Now, since in any society especially in the Periphery, as Zacharias (2003) and Ranta (2004) argue, English language teachers and ELT professionals' attitudes are revealing in any study in the field of ELT and their beliefs play a central role in the delivery of language instruction, it seems essential for the language teachers themselves and the professionals, practitioners and the planners of ELT in such societies to be aware of the beliefs and attitudes they are operating from.

Certainly, the Iranian society as the main reference of this study which is experiencing the increasing presence of English and ELT is not an exception and can be a suitable source of study with respect to the mainstream versus critical pedagogy in ELT. Thus, this study, as part of a broader study, tried to survey the Iranian ELT community's attitudes to these two opposing approaches in ELT.

\section{Theoretical Framework}

Accepting this fact that possibly the most significant development in ELT in the 1990s was the acceptance of this idea that ELT is and always has been a profoundly and unavoidably political activity (Johnston, 2003), it is not surprising to announce that the globalization of ELT is no longer perceived as an inevitable, unproblematic and natural development which contributes to people's lives and helps develop international communication, but it is accused of helping to maintain unequal core-periphery relations and of suppressing diversity of language and thought in the world (Hall, 2000).

Facing these facts, there is no doubt that ELT is not regarded any longer as a safe and clean export (Baladi, 2007) and not considered as a purely instrumental advantage from Inner-circle countries to Outer and Expanding-circle countries (Davari, 2011).

Following these changes, as noted, in the field of applied linguistics, the emergence of a prominent intellectual shift, involving some new critical trends, has led to viewing English and ELT through different critical paradigms. Among them, critical pedagogy, having a well-developed tradition both theoretical and applied, enjoys an important position.

Emerging in the 1960s and 1970s, the concept of critical pedagogy has been significant in education, but it has been around in ELT profession for almost two decades (Canagarajah, 2005). According to Akbari (2008b), in spite of its potential implications, however, the practical implications of CP have not been well appreciated and most of the 
references to the term have been limited to its conceptual dimensions.

In Pennycook's (1990) terms, critical pedagogy is an approach to teaching and curriculum development that seeks to understand and critique the historical and sociopolitical context of schooling and to develop pedagogical practices that aim not only to change the nature of schooling, but the wider society. In Byean's (2011) words, in ELT, CP primarily prompts teachers to scrutinize English language in light of the historical, cultural, sociopolitical and economic issues. Given the complexity and the role of English, Norton and Toohey (2004) believe that CP asks teachers to surpass the view of English as simply a means of expression or communication, but a practice that constructs the way learners understand themselves, their sociohistorical surrounding and then possibility for the future. According to Rashidi and Safari (2011) also, trying to define CP to a practice-oriented stance, it is introduced not a set of ideas, but a way of doing learning and teaching.

Now, avoiding the common conceptual and theoretical dimensions of $\mathrm{CP}$, the main practical implications of $\mathrm{CP}$ for English language classroom in five categories are highlighted and shortly introduced.

\subsection{Using First Language as a Source}

The common practice in L2 professional literature has been the rejection of learner's L1 (Akbari, 2008b). Contrary to this tenet of the mainstream ELT, critical pedagogy tradition regards L1 as an asset facilitating communication in L2. In this regard, Ford (2009) maintains that Phillipson's (1992) Linguistic Imperialism has been particularly influential in critiquing this tenet of the dominant ELT paradigm that "English is being best taught monolingually" known as the "monolingual tenet". Introducing this tenet as the "monolingual fallacy", Phillipson (1992) argues this belief is rooted in the maintenance of colonial power and in misguided and negative beliefs about bilingualism.

In Akbari's (2008) words, the rationale for the total exclusion of L1 from classes must be sought mostly in the political, economic dimensions of L2 teaching and the inability of native English teachers to utilize the mother tongue potential of their learners. Ford (2009) also maintains that, in terms of classroom practices, the imposition of an English-only approach can be considered as authoritarian and reflecting a supposition of linguistic and cultural superiority. From a critical perspective, Akbari (2008b) notes that denying the significance and learners' first language is part of his or her identity and a force which has played a crucial role in the formation of that identity. In addition, as Ford (2009) writes, proponents of CP have argued that learners' freedom to use their L1 in the second language classroom is nothing less than an expression of "linguistic human rights".

\subsection{Basing Teaching on Learners' Local Culture}

Culture has always been treated as an indispensable part of any language teaching/learning situation (Akbari, 2008b). According to Davari (2011), one of the most controversial facets of the globalization of English and ELT is the relationship between English language and culture. In this regard, Wilson (2005) states that cultural homogenization or in many cases Americanization is a controversial aspect of globalization in ELT. Gray (2000) writes that topics are chosen in such a way that the target culture seems to uphold values and living standards that are better than those of the student's culture, leading to the perception that the target culture is superior to the student's. In his words, even if textbooks do contemplate topics such as poverty, hunger, or even discrimination, they are contextualized in Africa or the Muslim world, creating the idea that poverty or discrimination is nowhere to be found in Europe or the USA.

Alptekin (2002) believes that ELT is "enculturation" in which the learner acquires new cultural frames of reference and a new worldview, reflecting those of the target language culture of its speakers. Demonstrating the cultural load of ELT practices developed in the Center, Canagarajah (1999) maintains that English spread especially through ELT strengthens the cultural hegemony of the Center.

As Akbari (2008b) puts it, reviewing the current ELT textbooks and other ELT materials reveals that most of their cultural content has been from the target culture and its main justification has been that those who want to learn English want to communicate with the users of this language, and successful communication would not be possible without the learners' familiarity with the cultural norms of English speakers. In this case, Akbari insists on the fact that this assumption is only true for those who want to migrate to countries such as the US or UK for work or study. Moreover, in his words, due to the scope of English application both geographically and communicatively, most of the communication carried out in English is between people who are themselves the so-called non-native speakers of English with a distinct cultural identity of their own. Thus, there is little need in this context for the Anglo-American culture, since neither party is a native with whom the other interlocutor is going to identify. In addition, from a critical perspective, not only, reliance on one's own local culture has the added value of enabling learners to think about the different aspects of the culture in which they live and find ways to bring about changes in the society where change is needed, but also, such a reliance will make the learners critically aware and respectful of their own culture and prevent the development of a sense of inferiority which might result from a total reliance on the target 
language culture where only the praiseworthy features of the culture are presented (ibid.).

\subsection{Including real-life Local and Global Concerns as Teaching Topics}

Reviewing the topics of the current mainstream ELT textbooks indicates that most of the topics in these books are either Center-oriented or sanitized. According to Banegas (2010), such couresbooks are criticized not only for avoiding provoking topics, but also for presenting a romantic view of countries such as Britain or the USA. In his words, in an attempt to avoid some controversial and real issues, material writers opt for selecting themes and topics that are rooted in the British or American culture and lifestyle.

Concerning the Center-oriented textbooks, Gray (2000) maintains that it is precisely the ambassadorial aspect of the ELT couresbooks which has led to recent criticisms. Phillipson (1992) also sees the promotion of such global couresbooks as a government-backed enterprise with an economic and ideological agenda aims ultimately at boosting commerce and the dissemination of ideas.

Akbari (2008a) states that many of the textbooks are sanitized and neutralized to make sure they do not lose their market potential and in this process most of the topics of interest for a critical pedagogy are removed. In his terms, most of the topics one encounters in commercially prepared textbooks deal with harmless issues such as travel, shopping, holidays and food recipes, leaving little room for social transformation and political awareness rising. Hillyard (2005) points out that when we study the topics of such textbooks, there is little controversial material. On the contrary, we find themes such as the family, sport, hobbies, travel, pop culture, festivals from remote countries which bear no impact on students' lives, fashion and food, among others. Also according to Banegas (2010) recently for reasons generally attributed to the production and matching of mainstream couresbooks produced for the general EFL class regardless of where they are used, publishers avoid the inclusion of provocative topics in developing the units of work couresbooks may be divided into.

In CP, what is more essential for both teachers and students is being critically aware of issues surrounding them both locally and globally (Byean, 2011). Criticizing the topics presented in the mainstream materials, Banegas (2010) supports $\mathrm{CP}$ as an approach which critical teachers are empowered so that they can reject, criticize and adapt the materials they use in order to help their students develop their cultural thinking skills.

In addition to taking the local as its point of departure (Akbari, 2008b), CP insists on the incorporation of global issues and concerns in ELT, too. Matsuda (2006) points out since at present learners want to become effective users of English in the international context, some awareness of global cultures and issues needs to be fostered. In her words, such topics as world peace, environmental conservation and other relevant topics in the field of global education provide appropriate content for readings, class discussions and course assignments.

Since CP, insisting on improving critical thinking, aims to empower language learners and provides an opportunity for the learners to transform their lives, on the one hand, it is strongly suggested that the topics and content of textbooks, class discussions and course assignments are contextually and locally situated and on the other hand to be effective users of English in the global context, integrating global issues needs to be fostered. According to Rashidi and Safari (2011), for CP to be truly effective in an English language program, materials should simultaneously develop learners' language skills and their awareness of the social structures.

\subsection{Developing Materials in Periphery}

As Anderson (2003) regards, one of the tenets of the mainstream pedagogy in ELT refers to the belief that the best materials come from the Inner-Circle countries. From the CP standpoint, ELT materials developed in the Center suffer from serious challenges and weaknesses.

Gray (2002) maintains that one effect of globalization is the imposition of Center materials on the Periphery in the increasing spread of global ELT couresbooks which are thematically and culturally "inclusive" and "inappropriate". In her words, although coursebooks are designed explicitly for the teaching of English language, they are also highly wrought cultural constructs and carriers of cultural messages, In Akbari's (2008b) words, the current commercially produced coursebooks, which form the backbone of instruction in many mainstream language teaching contexts, do not meet the learners' needs as well as the curriculums' ends.

According to Rashidi and Safari (2011), with the spread of criticisms on the mainstream ELT, materials as the heart of educational setting also have gone under critical appraisal and many applied linguists question the content of mainstream ELT materials. Discarding the use of commercially produced textbooks, CP, considering the cultural issues as well as the social and educational aims, insists on the rationale for ELT materials development in the Periphery. 


\subsection{Valuing Non-native English Speaking Teacher}

The issue of Native-English-Speaking Teacher (NEST) and Non-Native-Speaking English Teacher (NNEST) has generated a controversial debate in the past, and it still continues to do so internationally. Many researchers demonstrate that this politically- and ideologically-oriented dichotomy endows tacit superiority and authority to NESTs while demoralizes the value of NNESTs in language teaching milieus. (Byean, 2011). While the mainstream ELT introduces the ideal teacher of English a native speaker, Phillipson (1992) obviously calls this tenet as" the native speaker fallacy". Canagarajah (1999) writes that the native speaker fallacy monopolizes the ELT teaching jobs in the periphery. Pennycook (1994) maintains that the native English speaker teacher (NEST) is one important aspect of the cultural and economic politics of ELT, which forms an integral part of the industrialization of ELT.

Given the complexity of the issue, CP claims that the dichotomy of NEST and NNEST be thoroughly discussed in the sociopolitical and sociocultural perspectives as related to the global spread of English and ELT. In Byean's (2011) words, in identifying the colonizing Western Center and the being-colonized Periphery, Phillipson challenges the validity of the native speaker fallacy which only serves the interests of the Center by a means of perpetuating the misconception that NESTs are the ideal teachers of English. Holliday (2006) also criticizes that the pervasive ideology of so-called Native-speakerism represents a Western Culture from which spring the ideals both of the English language and of English teaching methodology. Criticizing this prevalent labeling of NESTs being superior to NNESTs in language teaching, Liu (1999) maintains that NNESTs have been discriminated against in their job opportunities.

Insisting on the mere legitimacy of native speaker pronunciation, while the mainstream ELT rejects the World Englishes, Rajagopalan (2004) as an advocate of CP clearly asserts that English in its current status or as he calls it "World English" cannot be restricted to the native-speaker standards.

Having provided a brief review of the relevant literature, here the context in which our study was conducted is introduced. Then, the findings are presented.

\section{Methodology}

The methodology used in this research was mixed-method including both qualitative and quantitative methods and among the current typological approaches in mixed methods, Qualitative $\rightarrow$ QUANTITATIVE was used. Dörnyei (2007), considering it as a frequently recommended procedure for designing a new questionnaire which involves conducting a small-scale explanatory qualitative study first to provide background information on the context, to identify and narrow down the focus of the possible variables and to act as a valuable source of ideas for preparing the item pool for the purpose of questionnaire scale construction, states that over the past 15 years, mixed-method research has been increasingly seen as a third approach in research methodology. Thus, following this procedure, in the first phase, a qualitative method, i.e. conducting interview was used to describe Iranian ELT professionals' attitudes to CP. In the second phase, the researchers utilized a quantitative method, i.e. questionnaire administration, in order to identify and examine Iranian ELT university teachers and professionals' attitudes among the population.

\subsection{Qualitative Part}

The strategy used in the qualitative part was interview. To get their attitudes, the participants took part in a face-to-face semi-structured interview with one of the researchers. The sampling method in this phase of study was that of criterion-based selection. Our criteria were as follows: a) Ph.D. in TEFL, b) Having ideas or having published work on the topic. According to these criteria, six ELT professionals meeting the needed criteria participated in this phase. The data gathered in this phase were used mostly in preparing and enriching the questionnaire. In this phase, content analysis was used which yielded the items regarding the ELT professionals' attitudes, beliefs and perspectives toward the critical pedagogy with a specific reference to the Iranian context.

\subsection{Quantitative Part}

The participants of the second phase of study were 86 ELT professionals and university teachers (74 MA and 12 $\mathrm{PhD}$ ) throughout the country. Based on the data gathered in the first phase and the findings found from the literature in this field, a Likert-scale questionnaire was prepared by the researchers included 10 statements (see Appendix 1). Of them, 5 were related to critical pedagogy in ELT and 5 were about the mainstream ELT. It is worth noting that these statements were prepared on the basis of five categories. Before its actual administration, it was studied and revised repeatedly, and then for the purpose of content and linguistic validity, it was piloted with 14 university teachers having the given criteria. The responses to the questionnaire in pilot stage were fed into SPSS to analyze its reliability. The reliability coefficients were calculated repeatedly for each part. Employing Cronbach alpha, it turned out that the alpha coefficient was 81 . Moreover, on the basis of the feedbacks obtained, some modifications were done and in this stage the questionnaire was finalized. 


\subsection{Procedure}

More than 200 questionnaires were administered through face-to-face contact or email by the researchers themselves. Of them, 86 were returned. Thus, the response rates to them were about $43 \%$. In each one, namely the paper version and the electronic one, the purpose of the study and a request for participants were stated. The data were collected over a 6-week period.

\section{Findings}

The results of the questionnaire can be classified and analyzed under five categories:

\subsection{Using First Language as a Source}

As noted, while the common practice in ELT has been the rejection of first language, CP regards first language as a source which cannot be rejected in the process of English learning. Thus, to check the Iranian ELT community's attitude to this issue, two statements (No. $1 \& 4$ of the questionnaire) were proposed as follows:

1- English should be taught only through the medium of English.

4- First language can be used to facilitate communication and comprehension of English classes.

Concerning the first question which is known as one of the important tenets of the mainstream ELT, findings reveal that 51 agreed on this issue, 39 disagreed and the mean was 3.6. Regarding the second question, as one of the beliefs of $\mathrm{CP}$, findings show that 38 agreed on this issue, 46 disagreed and the mean was 2.8 .

Reviewing the findings on this category shows the Iranian ELT community tends mostly to the mainstream ELT and the common practice in ELT profession is dominant in this community.

\subsection{Basing Teaching on Learners' Local Culture}

In this category, as mentioned, CP insists on including local culture and avoiding the Center's culture in ELT. Thus to check the Iranian ELT community's attitudes on this topic, two statements (No. 3 \& 7) as following were proposed:

3- The cultural content of ELT materials should be from the English language.

7- Students' local culture can be a suitable content.

Regarding the first statement, known as a tenet of the mainstream ELT, findings reveal that only 28 agreed on this issue, 56 disagreed and the mean was 2.6. In other words, in this statement, the respondents tend to CP. Concerning the second statement in this category which is known as one of the important applications of $\mathrm{CP}$, findings show that 49 agreed, 31 disagreed and the mean was 3.2. Therefore, it is found that in this category, the Iranian ELT community tends mostly to $\mathrm{CP}$.

\subsection{Including real-life Local and Global Concerns as Teaching Topics}

In this category, which dealt with the inclusion of local as well as global issues and concerns as topics in ELT, two statements (No. $5 \&$ 9) were proposed as following:

5- Local and real-life concerns and experiences are not good topics in English classes.

9- Global issues and problems (environmental, social, etc. issues) can be a suitable source of English classes.

Regarding the first statement which is contrary to the $\mathrm{CP}$ tradition, findings show that only 27 agreed on this issue, 52 disagreed and the mean was 2.7. In other words, the respondents mostly tended to CP. With respect to the second statement which is known as one of the newly emergent applications of CP, findings reveal that 77 agreed on this issue, only 8 disagreed and the mean was 4 . In a more precise word, the Iranian ELT community, in this category, tends to $\mathrm{CP}$.

\subsection{Developing Materials in Periphery}

In this category, which is known as one of the most controversial issues in ELT, as noted, one of the tenets of the mainstream ELT refers to the belief that the best materials come from Center and such textbooks are appropriate for international use. Contrary to this given, $\mathrm{CP}$, challenging their appropriateness and relevance, insists on developing ELT textbooks locally. Thus, to survey the Iranian ELT community' attitude on this issue two statements (No. 2 \& 6) were proposed as follows:

2- The international coursebooks used for English instruction are culturally, socially and politically acceptable for our society.

6- It is a necessity for Iranian ELT professionals to develop materials and textbooks themselves.

Regarding the first question, dealing with the mainstream ELT, findings show that 27 agreed, 56 disagreed and the 
mean was 2.5. Concerning the second statement which is known as one of the important applications of CP, 50 agreed, 30 disagreed and the mean was 3.3. Reviewing the findings reveals that in this category also the Iranian ELT community tends mostly to $\mathrm{CP}$.

\subsection{Valuing Non-native English Speaking Teacher}

In this category, known as the native speaker tenet in mainstream ELT and the native speaker fallacy in critical pedagogy, two statements (No. $8 \& 10$ ) were proposed as follows:

8- Native speaker of English is the best teacher of English.

10- American or British pronunciations should not be the only standards in pronunciation.

Regarding the first statement which is known as one of the tenets of the mainstream ELT, findings show that in this statement only 19 agreed and most of them, namely 40 disagreed and the mean was 1.9. But, regarding the second statement, belonging to $\mathrm{CP}$, findings show that 28 agreed, 45 disagreed and the mean was 2.7 . In other words, the findings of these two statements seem not to be correspondent.

\section{Conclusions}

Reviewing the findings obtained from the questionnaires reveals that in three categories, namely 4.1) Basing teaching on learners' local culture, 4.2) Including real-life local and global concerns as teaching topics, and 4.3) Developing materials in Periphery, the ELT community clearly tends to CP. Studying the findings of other two categories ( $4.1 \& 4.5)$ shows that in the former, in both statements, the mainstream pedagogy in ELT is dominant, but in the latter, with respect to one statement, (No.8), CP is dominant, but regarding the other one (No.10) the common practice in ELT professional literature is significant. To deal with the findings to the point and to present a vivid picture of the Iranian ELT community's attitudes to CP, the researchers try to discuss the causes.

Regarding the categories (4.1), (4.2) and (4.3) which dealt with the topics of teaching and discussions, basing teachings on local culture, the inappropriateness of international coursebooks and the necessity of the Iranian ELT professionals in ELT textbooks development, the findings show they were clearly in line with CP. Undoubtedly, such consistency on these three relevant categories shows the critical view of the Iranian ELT community to the Center's materials and textbooks used in Iranian ELT context. Here, referring to the opinions of the participants in the first phase seems necessary. The main causes presented in this phase show that the materials in general and the contents and topics of teaching sources and discussions in particular are not socially and culturally appropriate and relevant to the Iranian society. In other words, in their opinions, while such materials are mostly publicized as appropriate for international use, they are obviously Center oriented. Moreover, in their views, the position of English in Iranian society as a foreign language was a reason not to include their cultural content as the main content. In fact, findings from two phases in these three categories indicate that $\mathrm{CP}$ is dominant.

Concerning the first category, namely (4.1), findings of the second phase indicate the common practice in ELT professional literature which insists on first language rejection is dominant. Here, reviewing the findings from the first phase shows that the participants' opinions were not correspondent. While three participants believed that first language could be used as a source in English language teaching, two participants maintained that avoiding first language in classrooms could be more fruitful. Regarding the last category (4.5), findings show that there is no consistency between two statements. While, they clearly do not accept native speaker teacher as an ideal one, they tend to standard native pronunciations. Facing this situation, the researchers believe that being non-native teachers themselves could be an important reason for their tendency to the superiority of non-native teachers. Moreover, as presented by the participants in the first phase, lack of familiarity of native teachers with social, cultural and religious atmosphere of our society can be troublesome. Regarding the second statement in this category, our findings show that for the Iranian ELT community the Center standards in pronunciation are very important. According to Davavri (2011), Shirazizadeh and Momenian, (2009) as well as Aghaei (2009) such a tendency might partly attribute to the position of English in Iranian society as a foreign language. Moreover, as Davari (2011) notes, this tendency might be related to the fact that some concepts including World Englishes and English as a lingua Franca (ELT) which are against the mere acceptability of Center's pronunciations do not have any notable position in ELT trend in this society.

Professionally speaking, the findings obtained from this study show that there is a growing critical recognition among the Iranian ELT professionals and language teachers. In other words, referring to the findings of this study as well as the growing works on some critical issues including linguistic imperialism, critical pedagogy, World Englishes, etc. by the Iranian ELT professionals and applied linguists, are signs of this community's tendency to critical approaches to ELT. 


\section{References}

Akbari, R. (2008a). Postmethod discourse and practice. TESOL Quarterly, 42(2), 641-652

Akbari, R. (2008b). Transforming lives: introducing critical pedagogy into ELT classrooms. ELT Journal, 62(3), 276-283. http://dx.dor.org/10.1093/elt/ccn025

Alptekin, C. (2002). Toward intercultural communicative competence. ELT Journal, 56(1), 57-64

Anderson, C. (2003). Phillipson's children. Language and Intercultural Communication, 3(1), 81-95

Banegas, D. L. (2010). Teaching more than English in secondary education. ELT Journal, 65(1), 80-82

Canagarajah, A. S. (1999). Resisting Linguistic Imperialism in English Teaching. Oxford: Oxford University Press.

Cnagarajah, S. (2005). Critical pedagogy in L2 learning and teaching, In E. Hinkel (ed.), Handbook of Research in Second LanguageTeaching and Learning. Mahwah, NJ: Lawrence Erlbaum Associates.

Cox, M. I. P., \& Assis-Peterson, A. A. d. (1999). Critical pedagogy in ELT: Images of Brazilian teachers of English. TESOL Quarterly, 33, 433-484

Dörnyei, Z. (2007). Research methods in applied linguistics. New York: Oxford University.

Ford, K. (2009). Principles and practices of L1/L2 in the Japanese University EFL classrooms. JALT Journal, 31(1), 63-80

Gray, J. (2000). The ELT coursebook as cultural artifact: how teachers censor and adapt. ELT Journal. 54(3), 244-253

Hillyard, S. (2005). Content with your content? Why teach Global Issues in ELT? In L. Angada (Ed.), 30th FAAPI Conference, Towards the Knowledge Society: Making EFL Education Relevant. Conference Proceedings. Cordoba, Argentina: Comunicarte.

Holliday, A. (2006). Native-speakerism. ELT journal, 60(4). 385-387. http://dx.dor.org/10.1093/elt/ccl030

Liu, J. (1999). Nonnative-English-Speaking Professionals in TESOL. TESOL Quarterly, 33(1). 85-102

Matsuda, A. (2006). Negotiating ELT assumptions in EIL classrooms. In J. Edge (Ed.), (Re)Locating TESOL in an Age of Empire. London: Palgrave. pp.158-170

Norton, B., \& Toohey, K. (2004). Critical Pedagogies and Language Learning. New York: Cambridge University.

Pennycook. (1990) Towards a critical applied linguistics for the 1990s. Issues in Applied Linguistics, 8-28

Pennycook, A. (1994). The Cultural Politics of English as an International Language. Essex: Longman Group Ltd.

Phillipson, R. (1992). Linguistic Imperialism. Oxford, Oxford University Press.

Rajagopalan, K. (2000). Critical Pedagogy and Linguistic Imperialism in the EFL Context. TESOL Quarterly. 9(4), 5-6

Rajagopalan, K. (2004). 'The concept of “World English" and its implications for ELT'. ELT Journal, 58(2), 111-117. http://dx.dor.org/10.1093/elt/58.2.111

Rashidi, R., \& Safari, F. (2011). A Model for EFL Materials Development within the Framework of Critical Pedagogy (CP). English Language Teaching, 4(2), 250-59. http://dx.dor.org/10.5539/elt.v4n2p250

Shirazizadeh, M., \& Momenian, M. (2009). From EFL to ELF: Spotting the Blind Spots. English as International Language Journal, 4, 44-65

\section{Appendix 1. Questionnaire}

\section{Dear Colleague}

We are doing a research on Iranian ELT professional and university teachers' attitudes to some principles and practices of English language teaching. Your participation in this survey will help us complete our study. Please kindly spare a few minutes of your time to fill out this questionnaire. Thank you for your cooperation.

Sincerely, 


\begin{tabular}{|c|c|c|c|c|c|c|}
\hline & & $\begin{array}{l}\text { Strongly } \\
\text { agree }\end{array}$ & Agree & Undecided & Disagree & $\begin{array}{l}\text { Strongly } \\
\text { disagree }\end{array}$ \\
\hline 1. & English should be taught only through the medium of English. & & & & & \\
\hline 2. & $\begin{array}{l}\text { The international coursebooks used for English instruction are } \\
\text { culturally, socially and politically acceptable for our society. }\end{array}$ & & & & & \\
\hline 3. & $\begin{array}{l}\text { The cultural content of ELT materials should be from the } \\
\text { English language. }\end{array}$ & & & & & \\
\hline 4. & $\begin{array}{l}\text { First language can be used to facilitate communication and } \\
\text { comprehension of English classes. }\end{array}$ & & & & & \\
\hline 5. & $\begin{array}{l}\text { Local and real-life concerns and experiences are not good } \\
\text { topics in English classes. }\end{array}$ & & & & & \\
\hline 6. & $\begin{array}{l}\text { It is a necessity for Iranian ELT professionals to develop } \\
\text { materials and textbooks themselves. }\end{array}$ & & & & & \\
\hline 7. & Students' local culture can be a suitable content. & & & & & \\
\hline 8. & Native speaker of English is the best teacher of English. & & & & & \\
\hline 9. & $\begin{array}{l}\text { Global issues and problems (environmental, social, etc issues) } \\
\text { can be a suitable source of English classes. }\end{array}$ & & & & & \\
\hline 10. & $\begin{array}{l}\text { American or British pronunciations should not be the only } \\
\text { standards in pronunciation. }\end{array}$ & & & & & \\
\hline
\end{tabular}

\section{Appendix 2. Findings}

4.1 Using first language as a source

\begin{tabular}{|c|c|c|c|c|c|c|}
\hline \multirow{4}{*}{$\begin{array}{l}\text { 1. English should be taught } \\
\text { only through the medium of } \\
\text { English. }\end{array}$} & & Strongly agree & Agree & Undecided & Disagree & Strongly disagree \\
\hline & $\mathrm{N}$ & 14 & 37 & 8 & 29 & 10 \\
\hline & & \multicolumn{2}{|c|}{ Agree } & Undecided & \multicolumn{2}{|r|}{ Disagree } \\
\hline & $\mathrm{N}$ & \multicolumn{2}{|l|}{51} & 8 & \multicolumn{2}{|r|}{39} \\
\hline$M=3.6$ & $\%$ & \multicolumn{2}{|c|}{59.3} & 9.3 & \multicolumn{2}{|r|}{45.3} \\
\hline
\end{tabular}

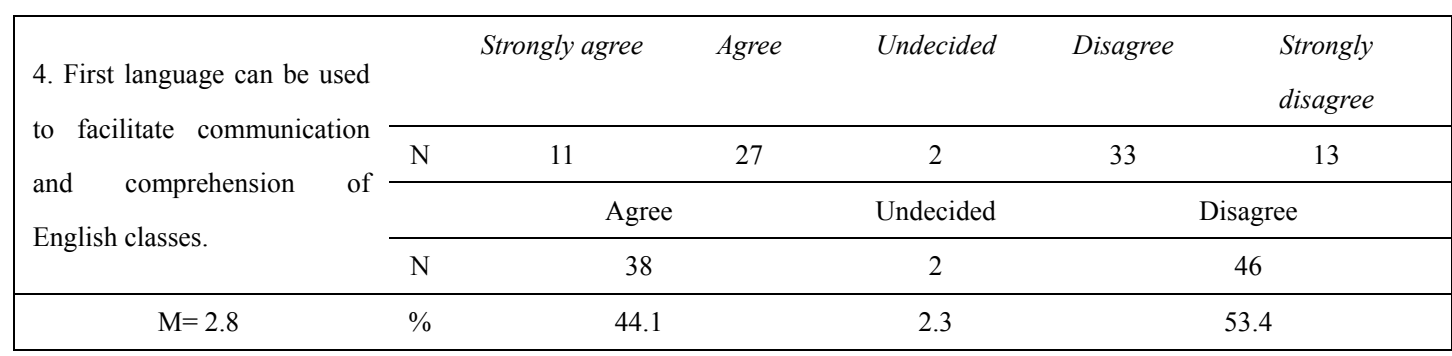


4.2 Basing teaching on learners' local culture

\begin{tabular}{|c|c|c|c|c|c|c|}
\hline \multirow{4}{*}{$\begin{array}{l}\text { 3. The cultural content of ELT } \\
\text { materials should be from the } \\
\text { English language. }\end{array}$} & & Strongly agree & Agree & Undecided & Disagree & Strongly disagree \\
\hline & $\mathrm{N}$ & 10 & 18 & 3 & 39 & 17 \\
\hline & & \multicolumn{2}{|c|}{ Agree } & Undecided & \multicolumn{2}{|c|}{ Disagree } \\
\hline & $\mathrm{N}$ & \multicolumn{2}{|l|}{28} & 3 & \multicolumn{2}{|r|}{56} \\
\hline$M=2.6$ & $\%$ & \multicolumn{2}{|c|}{32.5} & 3.4 & \multicolumn{2}{|r|}{65.1} \\
\hline
\end{tabular}

\begin{tabular}{|c|c|c|c|c|c|c|}
\hline \multirow{4}{*}{$\begin{array}{l}\text { 7. Students' local culture can } \\
\text { be a suitable content. }\end{array}$} & & Strongly agree & Agree & Undecided & Disagree & Strongly disagree \\
\hline & $\mathrm{N}$ & 15 & 34 & 6 & 20 & 11 \\
\hline & & \multicolumn{2}{|c|}{ Agree } & Undecided & \multicolumn{2}{|r|}{ Disagree } \\
\hline & $\mathrm{N}$ & \multicolumn{2}{|l|}{49} & 6 & \multicolumn{2}{|r|}{31} \\
\hline $\mathrm{M}=3.2$ & $\%$ & \multicolumn{2}{|c|}{56.9} & 6.9 & \multicolumn{2}{|r|}{36} \\
\hline
\end{tabular}

4.3 Including real-life local and global concerns as teaching topics

\begin{tabular}{|c|c|c|c|c|c|c|}
\hline \multirow{4}{*}{$\begin{array}{l}\text { 5. Local and real-life } \\
\text { concerns and experiences are } \\
\text { not good topics in English } \\
\text { classes. }\end{array}$} & \multicolumn{2}{|r|}{ Strongly agree } & \multirow{2}{*}{$\frac{\text { Agree }}{18}$} & \multirow{2}{*}{$\frac{\text { Undecided }}{10}$} & \multirow{2}{*}{$\frac{\text { Disagree }}{38}$} & \multirow{2}{*}{$\begin{array}{c}\text { Strongly disagree } \\
14\end{array}$} \\
\hline & $\mathrm{N}$ & 9 & & & & \\
\hline & & \multicolumn{2}{|c|}{ Agree } & Undecided & \multicolumn{2}{|r|}{ Disagree } \\
\hline & $\mathrm{N}$ & \multicolumn{2}{|c|}{27} & 10 & \multicolumn{2}{|r|}{52} \\
\hline $\mathrm{M}=2.7$ & $\%$ & \multicolumn{2}{|c|}{31.3} & 11.6 & \multicolumn{2}{|r|}{60} \\
\hline
\end{tabular}

\begin{tabular}{|c|c|c|c|c|c|c|}
\hline \multirow{4}{*}{$\begin{array}{l}\text { 9. Global issues and problems } \\
\text { (environmental, social, etc } \\
\text { issues) can be a suitable } \\
\text { source of English classes. }\end{array}$} & \multicolumn{2}{|r|}{ Strongly agree } & Agree & Undecided & Disagree & \multirow{2}{*}{ 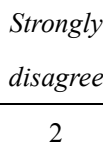 } \\
\hline & $\mathrm{N}$ & 25 & 52 & 1 & 6 & \\
\hline & & \multicolumn{2}{|c|}{ Agree } & Undecided & \multicolumn{2}{|c|}{ Disagree } \\
\hline & $\mathrm{N}$ & \multicolumn{2}{|l|}{77} & 1 & \multicolumn{2}{|c|}{8} \\
\hline $\mathrm{M}=4$ & $\%$ & \multicolumn{2}{|c|}{89.5} & 1.1 & \multicolumn{2}{|c|}{9.3} \\
\hline
\end{tabular}

\subsection{Developing materials in Periphery}

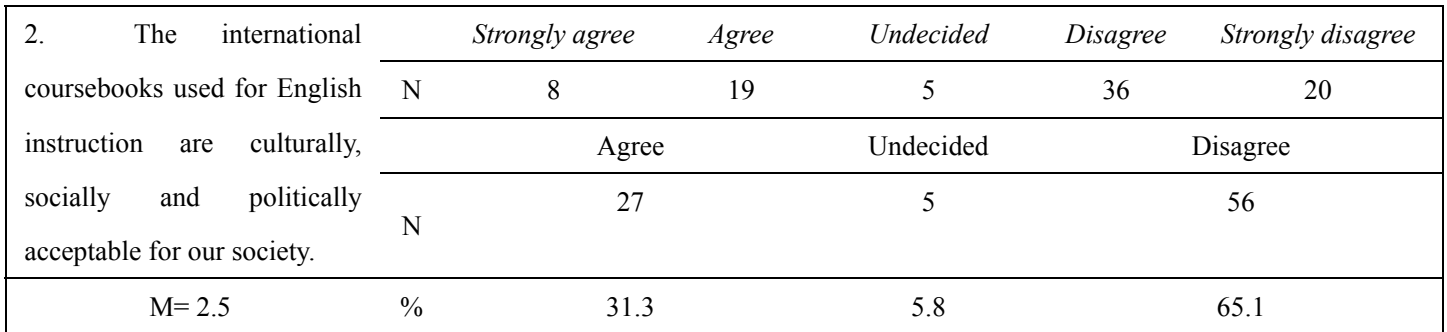

\begin{tabular}{|c|c|c|c|c|c|c|}
\hline \multirow{4}{*}{$\begin{array}{l}\text { 6. It is a necessity for Iranian } \\
\text { ELT professionals to develop } \\
\text { materials and textbooks } \\
\text { themselves. }\end{array}$} & \multicolumn{2}{|r|}{ Strongly agree } & Agree & Undecided & Disagree & Strongly disagree \\
\hline & $\mathrm{N}$ & 18 & 32 & 6 & 18 & 12 \\
\hline & & \multicolumn{2}{|c|}{ Agree } & Undecided & \multicolumn{2}{|r|}{ Disagree } \\
\hline & $\mathrm{N}$ & \multicolumn{2}{|c|}{50} & 6 & \multicolumn{2}{|r|}{30} \\
\hline $\mathrm{M}=3.3$ & $\%$ & \multicolumn{2}{|c|}{58.1} & 6.9 & \multicolumn{2}{|r|}{34.8} \\
\hline
\end{tabular}


4.5 Valuing non-native English speaking teacher

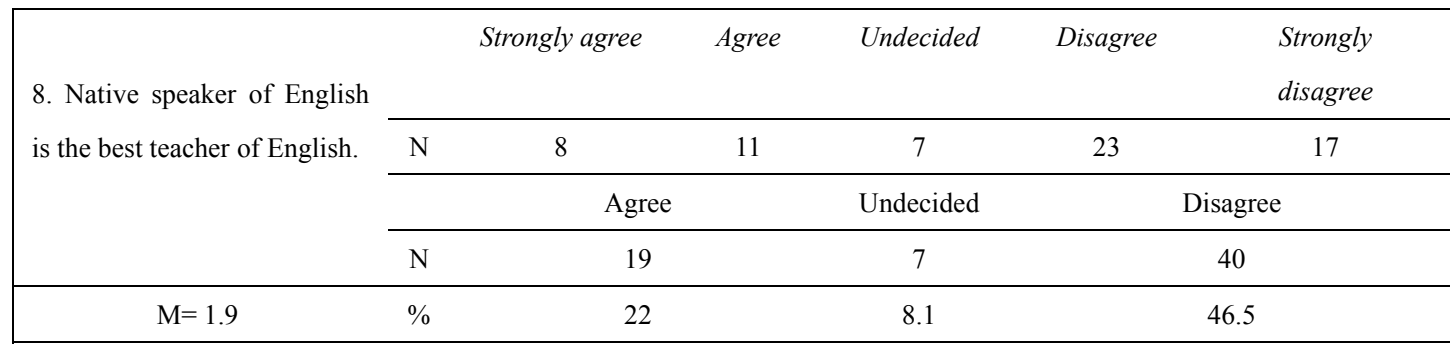

\begin{tabular}{|c|c|c|c|c|c|c|}
\hline \multirow{4}{*}{$\begin{array}{l}\text { 10. American or British } \\
\text { pronunciations should not be } \\
\text { the only standards in } \\
\text { pronunciation. }\end{array}$} & & Strongly agree & Agree & Undecided & Disagree & $\begin{array}{l}\text { Strongly } \\
\text { disagree }\end{array}$ \\
\hline & $\mathrm{N}$ & 10 & 18 & 13 & 30 & 15 \\
\hline & & \multicolumn{2}{|l|}{ Agree } & Undecided & \multicolumn{2}{|c|}{ Disagree } \\
\hline & $\mathrm{N}$ & \multicolumn{2}{|l|}{28} & 13 & \multicolumn{2}{|c|}{45} \\
\hline $\mathrm{M}=2.7$ & $\%$ & \multicolumn{2}{|l|}{32.5} & 15.5 & \multicolumn{2}{|c|}{52.3} \\
\hline
\end{tabular}

